\title{
Novel Structures Associated with Presumed Photoreceptors in the Aboral Sense Organ of Ctenophores
}

\author{
SIDNEY L. TAMM* \\ Bell Center, Marine Biological Laboratory, Woods Hole, Massachusetts 02543
}

\begin{abstract}
It is rare nowadays to find something that nobody has seen before, especially without using a new methodology or looking in a new place. Using conventional differential interference contrast (DIC) microscopy, I describe structures, heretofore not reported, in the well-studied aboral sensory complex, or apical organ, of ctenophores. Remarkably, the novel structures are placed symmetrically next to bodies believed to be photoreceptors. The nature and function of the new structures remain to be investigated.

Aboral and lateral differential interference contrast (DIC) microscopic views of the living apical organ in larvae or dissected adult tissue of Mnemiopsis leidyi show four groups of projections rising symmetrically from the concave, thickened epithelial floor (Fig. 1). These projections are called bristles because of their appearance, even though they can flex. Each group of bristles is located next to one of four crescent-shaped groups of dense structures, known as lamellate bodies (1), in the epithelial floor (Fig. 1). By DIC microscopy, a group of lamellate bodies resembles a bunch of bananas on a tree, each banana presumably representing a single cell (Fig. 2). The four lamellate body groups lie on either side of the sagittal plane, in two pairs extending from opposite sides of the central statocyst (Figs. $1,2)$. The lamellate bodies consist of onion-like whorls of coiled membranes derived from ingrown $9+0$ cilia $(1,2)$, and are presumed to be photoreceptors. In through-focus aboral images of the concave epithelial floor of the apical organ, the four bristle groups appear to stand up over the outer ends of the four groups of lamellate bodies (Fig. 2). However, in lateral views of tissue slices parallel to the sagittal plane, the bristle groups are not part of the lamellate
\end{abstract}

Received 29 March 2016; accepted 2 June 2016.

* To whom correspondence should be addressed. E-mail: tamm@bu.edu bodies, but arise a short distance away from the outer ends of the lamellate body groups, with one bristle group close to each group of lamellate bodies (Fig. 3). Longitudinal views of the curved epithelial floor avoid the depth of focus artifact of apparent overlap of bristle groups and lamellate bodies in aboral images. In lateral views of tissue slices along the sagittal plane, slight adjustment of microscope focus brings either member of a pair of bristle groups into sharp view. Sagittal plane views also show that the bristles incline toward the statocyst at the center of the apical organ, due to the concavity of the epithelial floor (Fig. 3). Tentacular plane slices focused above the statolith and close to the coverslip show a pair of bristle groups side by side, apparently over two groups of lamellate bodies seen end on (Fig. 4). Again, this is a depth of focus artifact along the Z-axis. The lower pair of bristle groups is too deep in the tissue to image clearly.

A group of bristles resembles a conical brush, with the bristles diverging from the base. Bristles vary in length from $43 \mu \mathrm{m}$ to $85 \mu \mathrm{m}$, with a mean length of $61 \mu \mathrm{m}(\mathrm{SD}=12$, $n=46)$. Individual bristles have a wider base, measuring 3-4 $\mu \mathrm{m}$ in diameter, which tapers to a pointed tip $\leq 1 \mu \mathrm{m}$ in diameter (Figs. 3, 4).

The four groups of bristles contain similar numbers of bristles, ranging from 4 to 9 , with a mean of 7 bristles per group ( $\mathrm{SD}=2, n=46$ ). Tangential views of the epithelial surface at the base of a bristle group show that the component bristles arise in a roughly circular array, whose outside diameter is about $15 \mu \mathrm{m}$. Measurements of bristle groups in profile views (sagittal or tentacular plane) confirm the $\sim 15$ - $\mu \mathrm{m}$-diameter size at the base (Figs. 3, 4). It was not possible to determine whether all the bristles in a group arise from a single cell or from more than one cell.

The tips of the bristles may extend above the top of the 


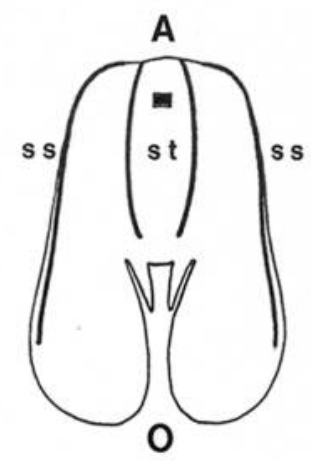

A

B
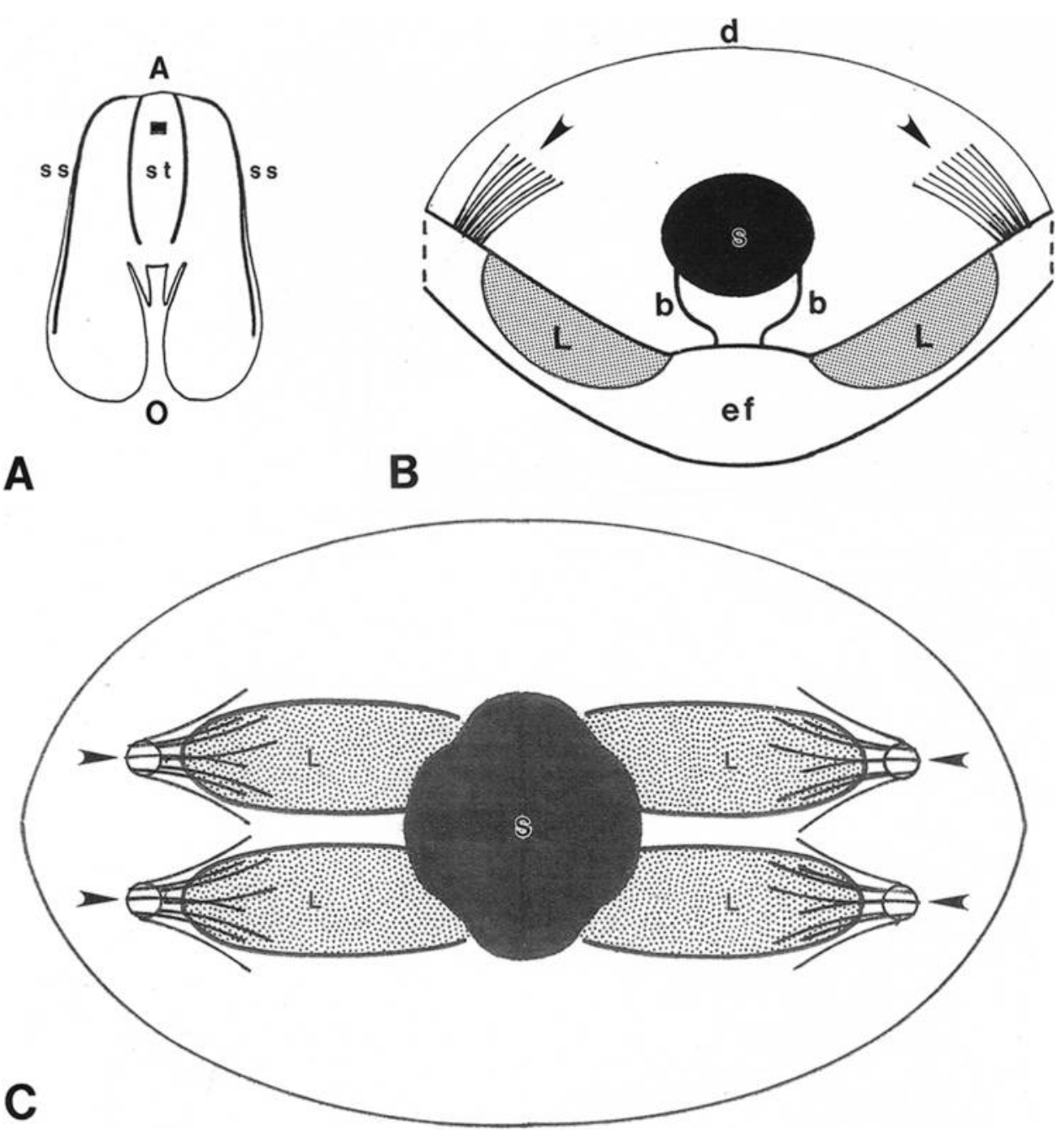

Figure 1. Diagram of the location, orientation, and arrangement of bristle groups in the apical organ of Mnemiopsis. (A) Whole animal viewed laterally in the sagittal plane (perpendicular to the tentacular plane). The apical organ is located in the small black box near the aboral end (A, upward). Two rounded lobes project downward from the oral end $(\mathrm{O})$. The longer subsagittal (ss) and the shorter subtentacular (st) comb rows are shown by heavy lines. (B) Higher-magnification view of the apical organ in the sagittal plane. The statolith (s) is supported by balancer cilia (b) projecting from the epithelial floor (ef) of the statocyst cavity, which is enclosed by dome cilia (d). One member of each pair of lamellate body groups (L; stippled) in the epithelial floor is shown on opposite sides of the statolith. One member of each pair of bristle groups projects from the floor (arrowheads) next to the outer ends of the lamellate body groups, on opposite sides of the statolith. (C) Aboral view of the apical organ, with the sagittal plane oriented horizontally and the tentacular plane oriented vertically. The major axis of the superellipsoidal statolith (s) runs in the tentacular plane and the minor axis in the sagittal plane, with four notches where the distal regions of the four balancers (not shown) enter the statolith (see 4). Four groups of lamellate bodies (L; stippled) lie in the epithelial floor in two pairs along the sagittal plane on opposite sides of the statolith. Four groups of bristles (arrowheads) project from the floor next to the outer ends of the four lamellate body groups. The bristles are foreshortened for a perspective view from above the epithelial floor. The oval boundary of the floor is the base of the dome cilia.

statolith, depending on the position of the statolith with respect to gravity. At right-angle orientations to gravity $\left(90^{\circ}\right.$ or $\left.270^{\circ}\right)$, the statolith is displaced downward, toward the lower bristle groups. In these cases, the statolith does not appear to touch or deflect the tips of nearby bristles (Fig. 3).
The distal regions of the bristles usually sway weakly to and fro in an apparently random motion. Rarely, a group of bristles makes a rapid and concerted bending movement. In two such instances, which were recorded in different sagittal plane slices tilted at $90^{\circ}$, a bristle group on the lower side of the statocyst suddenly flopped to the 

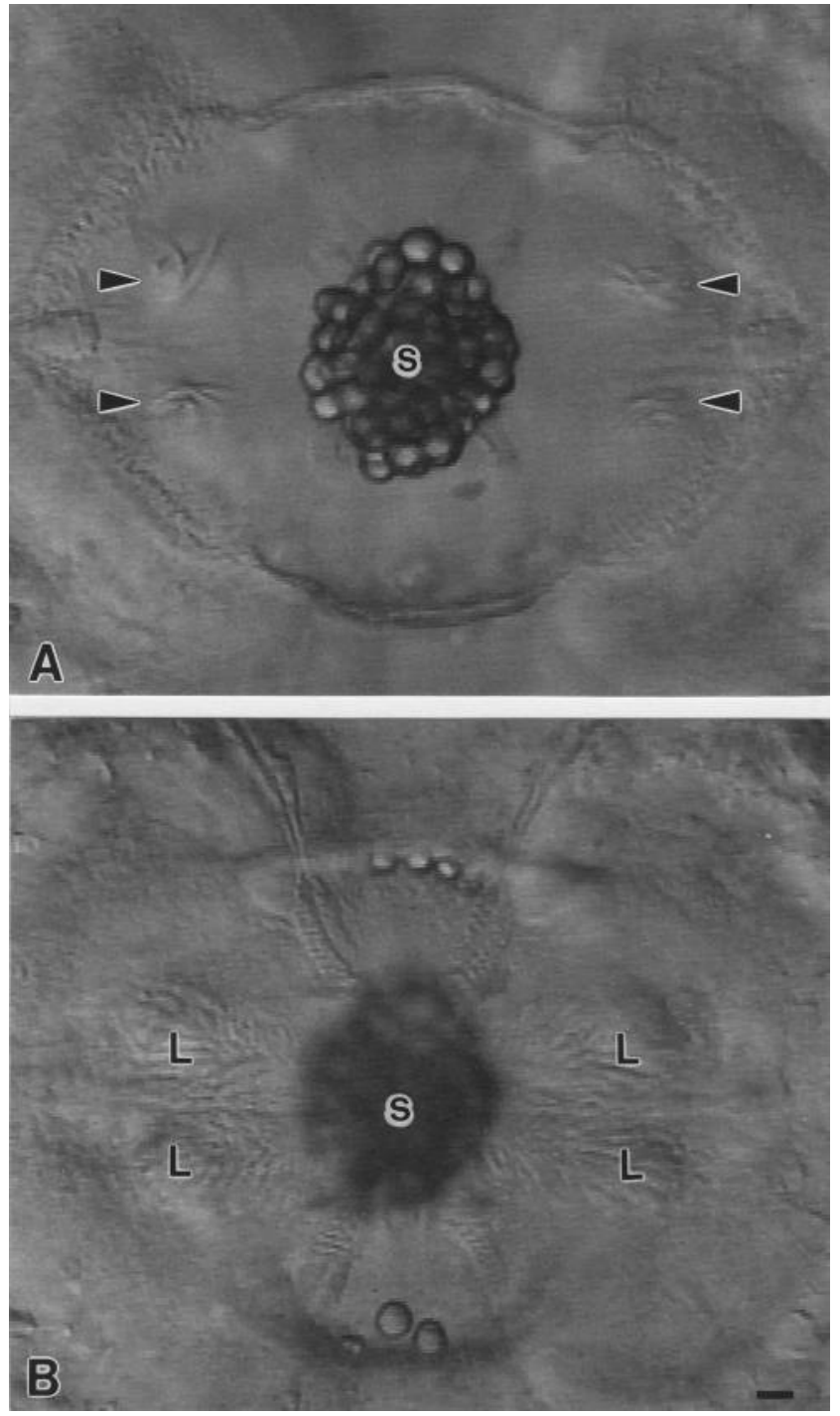

Figure 2. Differential interference contrast (DIC) microscopic aboral views at two focal levels of the apical organ of a 9-mm Mnemiopsis larva; the sagittal plane is oriented horizontally and the tentacular plane vertically. (A) Upper focus above the epithelial floor shows the statolith (s) composed of refractile lithocytes. A pair of bristle groups (arrowheads) is shown on opposite sides of the statolith, along the sagittal plane. The bases and tips of the bristles are out of focus. Waves of beating on the surrounding dome cilia are partially visible. (B) Lower focus on the epithelial floor shows a pair of lamellate body groups (L) on either side of the statolith (out of focus) along the sagittal plane. Three developing refractile lithocytes are present in opposite sides of the floor, along the tentacular plane (see 4). Bar, $10 \mu \mathrm{m}$.

epithelial floor, towards the nearby ciliary dome, then straightened immediately, returning to its previous upright stance (Fig. 5). The flop happened only once during the period of observation of the tissue preparation, and occurred without any visible changes in the activity of balancers, ciliated groove cilia, bridge cilia (see 3), or waves on the dome cilia (see 4). The adjacent member of the pair of bristle groups did not execute a flop, but remained in its normal upright posture. In the example shown, the complete cycle of bending and recovery took $\sim 3$ seconds (Fig. 5).

Bristles were observed on the epithelial floor next to lamellate bodies in all sizes of Mnemiopsis examined, except for very early larval stages. Nearly all of the smallest free-swimming larvae (i.e., 13 of 14), measuring $0.5-1 \mathrm{~mm}$ along the oral-aboral axis, lacked bristles by DIC microscopy, yet possessed a dome and four balancers supporting a small statolith. In slightly larger larvae, 1-2 mm long, bristles were present in a majority of larvae examined (i.e., 6 of 9). Thus, bristles arise soon after embryos hatch and become free-swimming. Whether bristles persist or are replaced (turnover) during adult life is unknown.

Bristle groups of similar appearance and arrangement next to groups of lamellate bodies are found in the apical organ of Pleurobrachia pileus and Beroë ovata. The main features of bristle groups as described in Mnemiopsis may therefore be characteristic of the apical organs in many, if not all, ctenophores.

To my knowledge, these groups of bristle-like projections on the epithelial floor of the ctenophore apical organ have not been described. Previous anatomical studies of ctenophore apical organs relied principally on histological staining or transmission electron microscopy (TEM) of fixed material $(1-3,5-7)$. The absence of any mention of these bristles in the literature is unlikely to be due to their destruction during fixation procedures, since bristles are preserved in the apical organs of Mnemiopsis that were fixed for TEM (Tamm, unpubl. data).

In my experience, the ability to visualize the bristles in living animals depends on attentive observation of either larvae immobilized under a coverslip or carefully oriented dissections of tissue slices of adult apical organs that allow views unobstructed by surrounding tissue and mesoglea. DIC microscopy is preferable to phase-contrast or brightfield optics for this purpose.

The existence of the bristles raises obvious questions. What is the nature of these projections and the cells that bear them? Future TEM studies should reveal the ultrastructure and possible type(s) of cytoskeletal elements within the bristles, such as actin, microtubules, or other structures. Fluorescent staining with specific probes may identify the chemical nature of specific bristle components. The structure of the bristle base at its transition into the cell body will be important to resolve. Possible junctions or synapses between bristle cells and adjacent lamellate body cells, nervous elements, or other types of cells in the epithelial floor need to be identified and mapped.

The motility of the bristles and bristle groups raises still more questions. Do the weak, but continuous swaying 

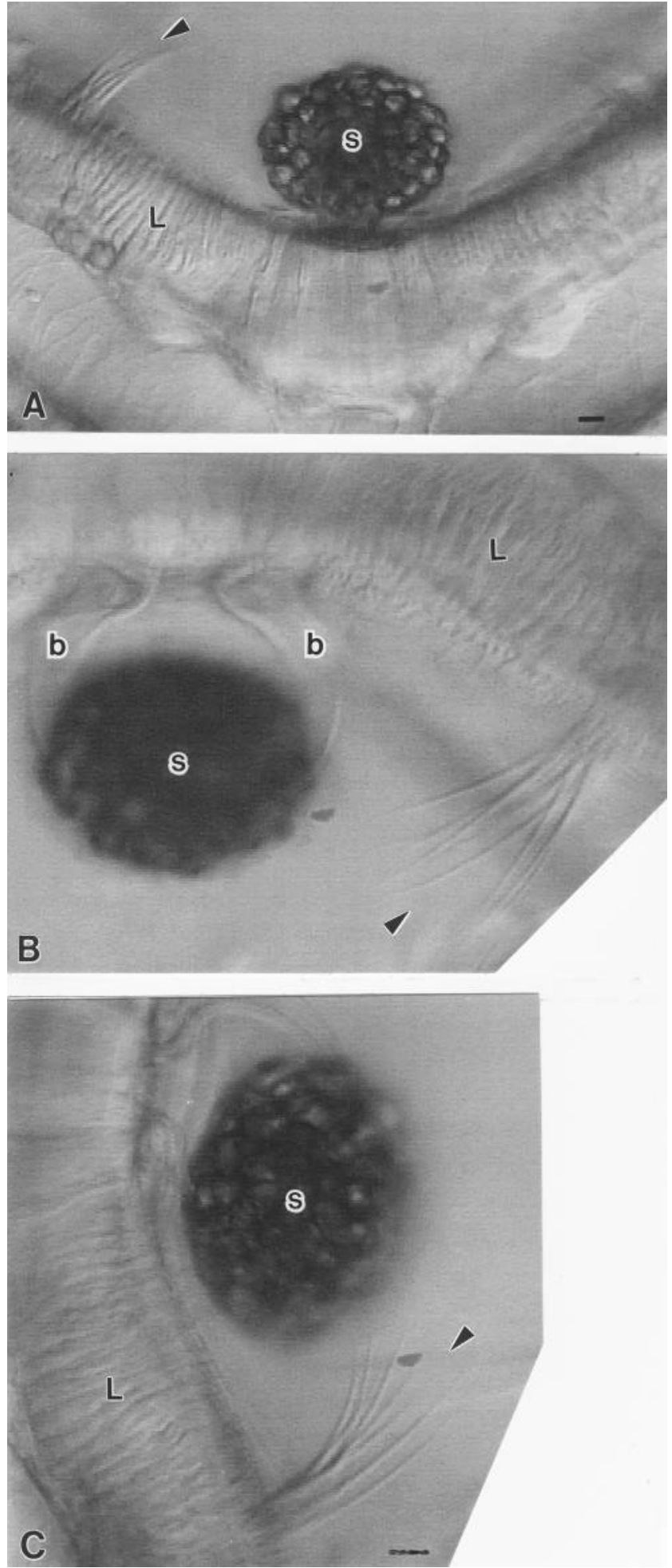

Figure 3. Differential interference contrast (DIC) microscopic views of bristle groups and lamellate bodies in a 1-2-mm-thick tissue slice cut parallel to the sagittal plane from a $4.5-\mathrm{cm}$ animal. The slide could be rotated in a vertical plane with respect to gravity (see 16). (A) Lowmagnification view, at $0^{\circ}$-orientation, of the concave epithelial floor with a bristle group (black arrowhead) on the left, inclined toward the statolith (s).

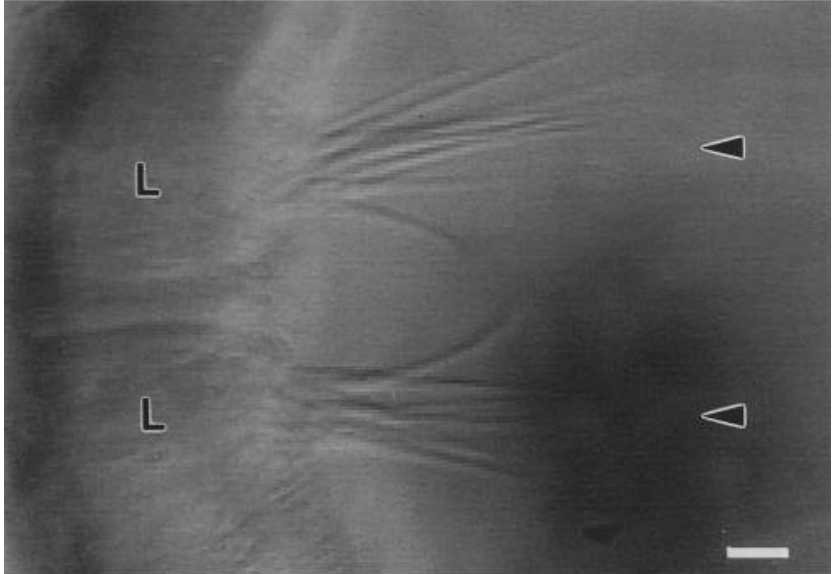

Figure 4. Differential interference contrast (DIC) microscopic view of a pair of bristle groups and lamellate bodies in a tentacular plane slice from a $4-\mathrm{cm}$ adult tilted $90^{\circ}$. The fuzzy dark mass is the out-offocus statolith, displaced downward by gravity. The two bristle groups (black arrowheads) of the pair lie side by side, close to (but not over) the outer ends of a pair of lamellate body groups (L) seen end on. Bar, $10 \mu \mathrm{m}$.

movements of bristles represent active movements, or passive responses to water currents set up under the enclosing dome by the beating of resident cilia? Water currents in the statocyst cavity have not been tracked systematically by particles or dyes. During a previous study of lithocyte transport on balancers (8), I noticed that free lithocytes, dissociated from the statolith, are often whirled or spun about by water currents under the dome (Tamm, unpubl. data).

The sudden bending and recovery movement, or flop, of a bristle group seems less likely to be a passive response, since it occurs only rarely and without detectable accompanying changes in ciliary activity or mechanical disturbances. Moreover, the adjacent bristle group of a pair does not flop, but instead remains upright. This behavior shows that bristles can certainly be flexible. If a flop is an active movement of a bristle group, then a motile mechanism must exist in bristles and/or their cell bodies.

Figure 3. (Continued) (The oral-aboral axis is vertical, with the aboral end facing up.) A crescent-shaped group of lamellate bodies (L) in longitudinal profile lies between the bristle group and the compressed balancer cilia supporting the statolith. The lamellate body groups and bristle groups on the right side of the statolith are out of focus. Bar, 10 $\mu \mathrm{m}$. (B) Higher-magnification view, at $180^{\circ}$-orientation, of the full length of the same bristle group (black arrowhead) and the group of lamellate bodies (L). (The oral-aboral axis is vertical, but the aboral pole faces down.) Note the statoliths (s) hanging from the sickle-shaped balancers (b). (C) At $90^{\circ}$-orientation, with the oral-aboral axis horizontal and the aboral pole to the right, the same bristle group (black arrowhead) and group of lamellate bodies (L) are on the lower side of the statolith (s), which is displaced downward, but does not touch the tips of the bristles. Bar: $10 \mu \mathrm{m}$ (B) (C). 

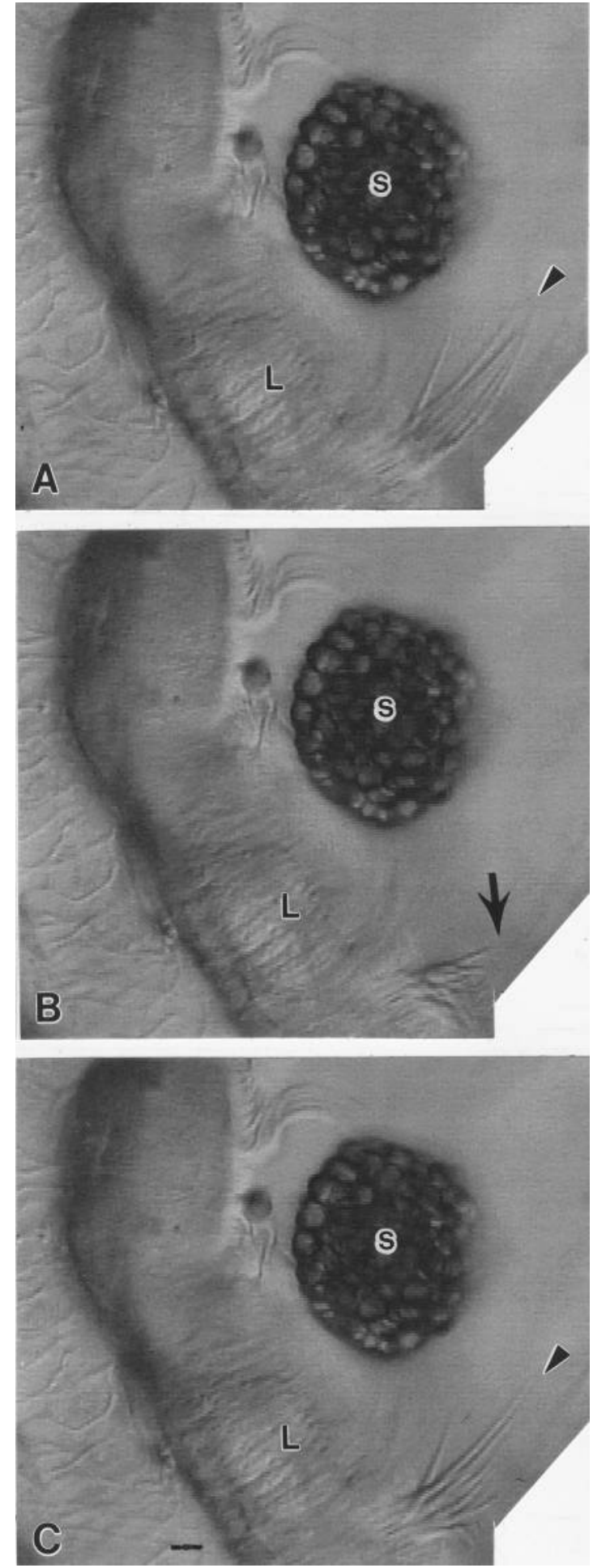

Figure 5. Flop of a bristle group in a sagittal slice tilted $90^{\circ}$. (A) The statolith (s) is displaced downward toward a lower pair of bristle groups, only one of which is in focus (black arrowhead), adjacent to a lamellate body group (L). (B) The bristle group flopped downward (black arrow) toward the dome cilia 1.5 seconds later. (C) The bristle group returned to its upright position (arrowhead) in another 1.5 seconds, completing the cycle. The adjacent bristle group of the pair (not shown) did not flop. Bar, $10 \mu \mathrm{m}$.
These observations all point to the main question: what is the function of the bristles? Two features suggest that bristles may be sensory receptors or structures related to sensory organelles. First, they project from the epithelial surface. Two other kinds of shorter projections from epithelial cells are widely distributed over the epidermis of a variety of ctenophores: non-motile cilia with a remarkable, onion-like root structure, and thick pegs containing a large bundle of actin filaments (5, 6, 9-15). Both types of projections may occur on the same epithelial cell $(11,13)$. Ultrastructural evidence for synaptic contacts of these cells onto adjacent neurites and gland cells indicates that the cells are sensory receptors $(11$, 12). Experiments on the fingers of Leucothea, which possess both types of projections, suggest that the nonmotile, onion-root cilia are mechanoreceptors that transduce water disturbances by prey to muscular responses of the fingers, possibly for prey capture (10).

Are the bristles mechanoreceptors for sensing displacements of the statolith during changes in the orientation of a ctenophore to the direction of gravity? At maximum body tilt $\left(90^{\circ}\right.$ or $\left.270^{\circ}\right)$, the downwardly displaced statolith does not appear to touch or deflect nearby bristles (Fig. 3), indicating that their role in geotaxis is unlikely. Instead, deflections of the mechanoresponsive pacemaker balancer cilia by the statolith have been shown to mediate geotactic behavior $(4,14-16)$.

Second, it is remarkable that the geometrical arrangement of the four bristle groups corresponds so closely to that of the four groups of lamellate bodies, which ultrastructural (1) and molecular-genomic evidence (17) indicate are photoreceptors. Not believing in anatomical coincidences leads one to believe that the bristle groups may somehow be involved in photoreception by ctenophores.

\section{Acknowledgments}

I thank Mark Terasaki for help and support, and Susan Banks of the Bell Center for expert assistance in scanning figures. This work was supported by the Fund for Science.

\section{Literature Cited}

1. Horridge, G. A. 1964. Presumed photoreceptive cilia in a ctenophore. Q. J. Microsc. Sci. 105: 311-317.

2. Krisch, B. 1973. Über das Apikalorgan (Statocyste) der Ctenophore Pleurobrachia pileus. Z. Zellforsch. 142: 241-262.

3. Tamm, S. L., and S. Tamm. 2002. Novel bridge of axon-like processes of epithelial cells in the aboral sense organ of ctenophores. J. Morphol. 254: 99-120.

4. Tamm, S. L. 2014. Formation of the statolith in the ctenophore Mnemiopsis leidyi. Biol. Bull. 227: 7-18.

5. Chun, C. 1880. Die Ctenophoren des Golfes von Neapel, und der angrenzenden Meeres-Abschnitte. Fauna und Flora des Golfes von Neapel, Vol. 1, Monographie. Engelmann, Leipzig.

6. Hertwig, R. 1880. Ueber den Bau der Ctenophoren. Jenaische $Z$. Naturwiss. 14: 393- 457. 
7. Aronova, M. 1974. Electron microscopic observations on the aboral organ of ctenophores. Z. Mikrosk. Anat. Forsch. 88: 401-412.

8. Noda, N., and S. L. Tamm. 2014. Lithocytes are transported along the ciliary surface to build the statolith of ctenophores. Curr. Biol. 24: R951-R952.

9. Eimer, T. 1880. Ueber Tastapparate bei Eucharis multicornis. Archiv. Mikrosk. Anat. 17: 242-345.

10. Horridge, G. A. 1965. Non-motile sensory cilia and neuromuscular junctions in a ctenophore independent effector organ. Proc. R. Soc. Lond. B 162: 333-350.

11. Hernandez-Nicaise, M.-L. 1974. Ultrastructural evidence for a sensory-motor neuron in Ctenophora. Tissue Cell 6: 43-47.

12. Hernandez-Nicaise, M.-L. 1991. Ctenophora. Pp. 359-418 in Microscopic Anatomy of Invertebrates, Vol. 2, Placozoa, Porifera, Cnidaria, and Ctenophora, F. W. Harrison and J. A. Westfall, eds. Wiley-Liss, New York.
13. Tamm, S., and S. L. Tamm. 1991. Actin pegs and ultrastructure of presumed sensory receptors of Beroë (Ctenophora). Cell Tissue Res. 264: $151-159$.

14. Tamm, S. L. 1982. Ctenophora. Pp. 266-358 in Electrical Conduction and Behaviour in 'Simple' Invertebrates, G. A. B. Shelton, ed. Oxford University Press, Oxford.

15. Tamm, S. L. 2014. Cilia and the life of ctenophores. Invertebr. Biol. 133: $1-46$.

16. Tamm, S. L. 2015. Functional consequences of the asymmetric architecture of the ctenophore statocyst. Biol. Bull. 229: 173-184.

17. Schnitzler, C., K. Pang, M. L. Powers, A. M. Reitzel, J. F. Ryan, D. Simmons, T. Tada, M. Park, J. Gupta, S. Y. Brooks et al. 2013. Genomic organization, evolution, and expression of photoprotein and opsin genes in Mnemiopsis leidyi: a new view of ctenophore photocytes. BMC Biol. 10: 107-133. 